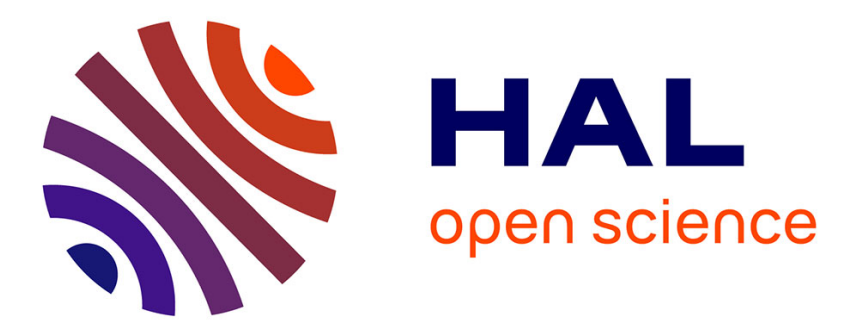

\title{
Atomic scale study of InP etching by Cl-Ar ICP plasma discharge
}

\author{
A. Rhallabi, R. Chanson, J.-P. Landesman, Christophe Cardinaud, M.-C. \\ Fernandez
}

\section{> To cite this version:}

A. Rhallabi, R. Chanson, J.-P. Landesman, Christophe Cardinaud, M.-C. Fernandez. Atomic scale study of InP etching by Cl-Ar ICP plasma discharge. European Physical Journal: Applied Physics, 2011, 53 (3), 10.1051/epjap/2010100056 . hal-00672785

\section{HAL Id: hal-00672785 \\ https://hal.science/hal-00672785}

Submitted on 22 Feb 2012

HAL is a multi-disciplinary open access archive for the deposit and dissemination of scientific research documents, whether they are published or not. The documents may come from teaching and research institutions in France or abroad, or from public or private research centers.
L'archive ouverte pluridisciplinaire HAL, est destinée au dépôt et à la diffusion de documents scientifiques de niveau recherche, publiés ou non, émanant des établissements d'enseignement et de recherche français ou étrangers, des laboratoires publics ou privés. 


\title{
Atomic scale study of InP etching by $\mathrm{Cl}_{2}$-Ar ICP plasma discharge
}

\author{
Ahmed Rhallabi, Romain Chanson, Jean Pierre Landesman, Christophe Cardinaud, Marie-Claude \\ Fernandez
}

Institut des Matériaux Jean Rouxel, CNRS - Université de Nantes, France

\begin{abstract}
A gas phase kinetic model combined to a 3D atomic etching model have been developed to study the etching process of $\mathrm{InP}$ under $\mathrm{Cl}_{2}$ - $\mathrm{Ar}$ ICP plasma discharge. A gas phase global kinetic model is used to calculate the reactive particle fluxes implied in the etching mechanisms. The 3D atomic InP etching model is based on the Monte-Carlo kinetic approach where the plasma surface interactions are described in the probability way. The coupling between the plasma chemistry model and the surface etching model is an interesting approach to predict the etched surface properties in term of the etch rate, the surface roughness and surface steochiometry as a function of the operating conditions.

A satisfactory agreement is obtained by comparing the experimental and the simulation results concerning the evolution of the main plasma discharge parameters such as the electron density and temperature versus the ICP source power for surface recombination coefficient of atomic chlorine fixed at $\gamma_{\mathrm{Cl}}=0.04$. On the other hand, simulation results show the effect of the operating conditions on the etched surface roughness and the etch rate evolutions with time in the early stage. Moreover, the simulation results show the correlation between the decrease of the ion to chlorine flux ratio and the decrease of the RRMS as a function of the pressure.
\end{abstract}

\section{Introduction}

Nowadays, plasma process represents one of the keys for the integration enhancement of electronic and optical devices. Indeed, it is now possible with plasma etching process using high density plasma reactors such as Inductive Coupled Plasma (ICP) to transfer nanometer scale patterns from the mask to the substrate [1-5]. The success of the high aspect ratio pattern transfer without geometrical defects [6-9] (bowing, undercut, trenching,..) is tributary of a good understanding of the physical and chemical mechanisms of the plasma discharge and the surface kinetic processes. Some attempts of $\mathrm{Si}$ and III-V pattern transfer development like photonic crystals, deep trenches or mesa structures are achieved by plasma etching [10-16]. For this type of devices, dry etching based on the plasma discharge is developed by using a variety of gas like $\mathrm{Cl}_{2}$ [13-15], $\mathrm{SiCl}_{4}[10,16]$, etc. Experimental studies concerning the chloride plasma discharges have been carried out to investigate the electrical and kinetic properties of mentioned plasma discharges [17-23]. Modelling of plasma discharge in different degrees of complexity, specially, for the chloride precursors have been developed by using different approaches [9,24-28] such as fluid model, Particle In Cell or global model to model the electro-magnetic phenomena transport of charged species in different types of reactors.

Some atomic approaches of surface kinetic model have been developed to study the plasma surface interaction phenomena for etching processes. The first one concerns the molecular dynamics which is based on the solving of the equation of motion for a system of interacting particles. Newton's equations of motion are integrated numerically to compute the atom's trajectory [34,35]. Such method is developed to compare physical sputtering and chemical 
sputtering for the silicon etching by fluoride precursors [34]. The accurate information obtained with this method is conditioned by the good knowledge of the interaction potential functions. This method is applied for small etched surfaces because of the time consuming. The second method is based on the Monte-Carlo kinetic method [36] where the initial etched material is represented in 3D layer. Such method allowed to easily take into account of several adsorbed precursors impinging on the substrate surface and site identities during the etching process. The Monte-Carlo method was already applied to the InP etching by $\mathrm{CH}_{4}-\mathrm{H}_{2}$ plasma [36]. It allowed to show the role of both the chemisorption probabilities of $\mathrm{CH}_{3}$ and $\mathrm{H}$ and the surface migration process on the phosphorus depletion in the shallow layers [36].

In this study, we have developed a kinetic model based on the global approach in which the densities of neutral and charged species produced in plasma are assumed spatially uniform [2628]. Its advantage is to give approximate information about the reactive species transport with a reasonable simulation time. This model is applied to the Inductive Coupled Plasma (ICP) discharge of $\mathrm{Cl}_{2} / \mathrm{Ar}$. The model consists in the calculation of the densities of species from a set of mass balance equations describing the major gas-phase processes. The gas phase kinetic model is connected to 3D etching model in order to predict the etched InP material properties as a function of the operating conditions. 3D Monte-Carlo method is applied to follow the properties of the etched InP surface evolution with time.

In section 2, the gas phase model is described and a discussion of the kinetic reactions is presented. Results from this model are given and comparisons between the simulations and the experiments have been presented. The 3D Monte-Carlo etching model is described in section 3 and includes hypothesis justifications. The simulation results from the etching model are presented showing the interest to couple the plasma kinetic model to the etching model in the prediction of the etched surface properties versus the operating conditions. Concluding remarks are in section 4.

\section{Global kinetic Model}

The gas phase model is based on the time dependent resolution of the mass balance equations of main chemical species existing in the reactor. Thus, the rate equation for the primary molecules $\left(\mathrm{Cl}_{2}\right.$ and $\mathrm{Ar}$ in our case $)$ with density $N_{i}\left(\mathrm{i}=\mathrm{Cl}_{2}\right.$ or $\left.\mathrm{Ar}\right)$ is given as [26-27]:

$$
\frac{d N i}{d t}=x \frac{Q}{V}-\sum_{l} k_{e 1}(T e) N_{i} n_{e}+\sum_{n} k_{e n}(T e) N_{n} n_{e}-\sum_{m} k_{m i}(T) N_{i} N m+\sum_{l m} k_{m l}(T) N_{l} N_{m}+\sum_{l} k s_{l} N_{l}-\frac{N i}{\tau_{R}}
$$

where the first term represents the source term which $\mathrm{Q}$ is the total flow rate, $\mathrm{V}$ is the reactor volume, $\mathrm{x}$ is the fraction of the primary molecule $\left(\mathrm{Cl}_{2}\right.$ or $\left.\mathrm{Ar}\right)$ and $\tau_{R}$ is the residence time of molecules in reactor. The second term represents the loss rate of chlorine/argon by electron impact which $k_{e l}$ is the kinetic constant of the $1^{\text {th }}$ reaction by electron impact with the molecule (i). The third term is the production rate of chlorine/argon by electron impact with species (n). The fourth term is the loss rate of chlorine/argon by reaction between (i) and (m) species. The fifth term is the production rate of the species (i) by reaction between (l) and (m) species, which $\mathrm{k}_{\mathrm{ml}}$ is the kinetic constant of the reaction between $(\mathrm{l})$ and $(\mathrm{m})$. The sixth term is the production rate of chlorine/Argon on the surface due to the transformation of the species (l) to (i). For Ar, $\left.\left.\sum_{l} k_{s l} N_{l}=k_{21} \mid A_{r}^{*}\right\rfloor+k_{20} \mid A_{r}^{+}\right\rfloor$while for $\mathrm{Cl}_{2}, \sum_{l} k_{s l} N_{l}=\frac{1}{2} k_{17}[C l]+k_{19}\left[\mathrm{Cl}_{2}^{+}\right]$(see table 1). The last term is the loss rate by pumping. $\mathrm{T}$ and $\mathrm{T}_{\mathrm{e}}$ are the gas and electron temperatures respectively. For the other neutral and ion species the balance equations are given as [26-27]: 
$\frac{d N_{j}}{d t}=-\sum_{l} k_{l}(T e) N_{j} n_{e}+\sum_{n} k_{n}(T e) N_{n} n_{e}-\sum_{m} k_{m j}(T) N_{j} N m+\sum_{l m} k_{m l}(T) N_{l} N_{m}-k s_{j} N_{j}+\sum_{l} k s_{l} N_{l}-\frac{N_{j}}{\tau_{R}}(2)$ $k s_{j} N_{j}$ is the surface lost rate of $\mathrm{j}^{\text {th }}$ species. For the neutral species, $k s_{j}$ is determined as a function of the diffusion coefficient $D_{j}$ and diffusion length $\Lambda$ of the $\mathrm{j}^{\text {th }}$ species [27]:

$$
k s_{j}=\gamma_{j} \frac{D_{j}}{\Lambda^{2}}
$$

$\gamma_{\mathrm{j}}$ is the recombination coefficient on the surface of the $\mathrm{j}^{\text {th }}$ species. $\Lambda$ depends on the reactor geometry parameters. For a cylindrical reactor $\Lambda$ is given as [29]:

$$
\frac{1}{\Lambda^{2}}=\left(\frac{\pi}{L}\right)^{2}+\left(\frac{2.405}{R}\right)^{2}
$$

where $L$ and $R$ are the height and the radius of ICP reactor.

For the positive ion species, $k_{s j}$ is given as [27]:

$$
k_{s j}=2 u_{B, j}\left(R^{2} h_{L}+R L h_{R}\right) / R^{2} L
$$

where $u_{B, j}$ is the Bohm velocity. $h_{L}$ and $h_{R}$ are the ratio of the wall density to the bulk average density of species $\mathrm{j}$ for the walls located in the axial and the radial directions respectively [27].

The power balance equation is added to the plasma kinetic equation system to selfconsistently evaluate the electron temperature. It is given as [27,28]:

$$
\frac{\partial}{\partial t}\left(\frac{3}{2} q T_{e} n_{e}\right)=P_{R F}-P_{a b s}
$$

where $P_{R F}$ and $P_{a b s}$ are the RF power injected in the reactor and the power absorbed by plasma respectively. $\mathrm{P}_{\mathrm{abs}}$ is given as [27,28]:

$$
\mathrm{P}_{\mathrm{abs}}=\mathrm{P}_{\mathrm{ev}}+\mathrm{P}_{\mathrm{ew}}+\mathrm{P}_{\mathrm{iw}}
$$

where $P_{e v}$ is power losses for inelastic and elastic collisions by electron impact and $\mathrm{P}_{\mathrm{ew}}$ and $\mathrm{P}_{\mathrm{iw}}$ are power losses on the surface for electron and positive ions respectively. The addition of power equation to the kinetic system allows to self-consistently calculate the electron temperature and thus to deduce the chemical species densities as a function of the injected power in the ICP reactor.

The balance equation system is completed by the charge neutrality equation:

$$
n_{e}+\sum_{j} n_{j}^{-}=\sum_{j} n_{j}^{+}
$$

where $n_{j}^{-}$and $n_{j}^{+}$are the negative and positive ions respectively.

Table 1 shows kinetic reactions taken into account in the mass balance equations. The mass balance equations are applied to $\mathrm{Cl}_{2}, \mathrm{Cl}, \mathrm{Cl}_{2}{ }^{+}, \mathrm{Cl}^{+}, \mathrm{Cl}^{-}, \mathrm{Ar}, \mathrm{Ar}^{*}$ and $\mathrm{Ar}^{+}$which are considered as the dominant species in the $\mathrm{Cl}_{2} / \mathrm{Ar}$ plasma. Metastable states of $\mathrm{Cl}_{2}$ and $\mathrm{Cl}$ are not taken into account in the kinetic system. However, the reactions involving the metastable species are considered in the power balance equation because of the significant fraction of the injected power which is lost by the excitation processes (table2).

The differential equation system composed of equations $1,2,7,8$ is resolved from initial conditions until the study state when Te and all species densities become constant with time.

Tables 1-2 give the reactions taken into account in the system for the $\mathrm{Cl}_{2} / \mathrm{Ar}$ plasma mixture. The rate constants for electron impact are calculated knowing the electron cross sections and assuming a Maxwellian distribution of electron energy [27,28,30,31,43-53]. 


\begin{tabular}{|c|c|c|c|}
\hline \multicolumn{2}{|c|}{$\begin{array}{l}\text { Electron impact reactions } \\
\text { and volume reactions }\end{array}$} & \multirow{2}{*}{\begin{tabular}{|l} 
Reaction constants, $\mathbf{T e}(\mathbf{e V})$ \\
$k_{1}=9.2110^{-8} \exp (-12.9 / \mathrm{Te}) \mathrm{cm}^{3} / \mathrm{s}$
\end{tabular}} & \multirow{2}{*}{\begin{tabular}{|l|} 
References \\
$27,28,30$ \\
\end{tabular}} \\
\hline $\mathrm{k}_{1}$ & $\mathrm{e}+\mathrm{Cl}_{2} \rightarrow \mathrm{Cl}_{2}^{+}+2 \mathrm{e}$ & & \\
\hline $\mathrm{k}_{2}$ & $\mathrm{e}+\mathrm{Cl}_{2} \rightarrow \mathrm{Cl}^{+}+\mathrm{Cl}+2 \mathrm{e}$ & $k_{2}=3.8810^{-9} \exp (-15.5 / \mathrm{Te}) \mathrm{cm}^{3} / \mathrm{s}$ & $27,28,30$ \\
\hline $\mathrm{k}_{3}$ & $\mathrm{e}+\mathrm{Cl}_{2} \rightarrow \mathrm{Cl}^{+}+\mathrm{Cl}^{-}+\mathrm{e}$ & $k 3=8.5510^{-10} \exp (-12.65 / \mathrm{Te}) \mathrm{cm}^{3} / \mathrm{s}$ & $27,28,30$ \\
\hline $\mathrm{k}_{4}$ & $\mathrm{e}+\mathrm{Cl}_{2} \rightarrow 2 \mathrm{Cl}+\mathrm{e}$ & $k_{4}=3.8010^{-8} \exp (-3.824 / \mathrm{Te}) \mathrm{cm}^{3} / \mathrm{s}$ & 27,43 \\
\hline $\mathrm{k}_{5}$ & $\mathrm{e}+\mathrm{Cl}_{2} \rightarrow \mathrm{Cl}+\mathrm{Cl}^{-}$ & $\begin{array}{l}k_{5}=3.6910^{-10} \exp \left(-1.68 / \mathrm{Te}+1.457 / \mathrm{Te}^{2}\right. \\
\left.-0.44 / \mathrm{cm}^{3}+0.0572 / \mathrm{Te}^{4}-0.0026 / \mathrm{Te}^{5}\right)\end{array}$ & $27,28,30$ \\
\hline $\mathrm{k}_{6}$ & $\mathrm{e}+\mathrm{Cl} \rightarrow \mathrm{Cl}^{+}+2 \mathrm{e}$ & $\begin{array}{l}k_{6}=(\mathrm{Te} / 12.96)^{0.5} \exp (-12.96 / \mathrm{Te})\left(1.41910^{-7}\right. \\
-1.86410^{-8} \log (\mathrm{Te} / 12.96)-5.43910^{-8} \log (\mathrm{Te} / 12.96)^{2}+ \\
3.30610^{-8} \log (\mathrm{Te} / 12.96)^{3}-3.5410^{-9} \log (\mathrm{Te} / 12.96)^{4} \\
\left.\left.-2.91510^{-8} \log (\mathrm{Te} / 12.96)^{5}\right)\right) \mathrm{cm}^{3} / \mathrm{s}\end{array}$ & 27,31 \\
\hline $\mathrm{k}_{7}$ & $\mathrm{Cl}^{-}+\mathrm{Cl}_{2}^{+} \rightarrow \mathrm{Cl}+\mathrm{Cl}_{2}$ & $k_{7}=5 \times 10^{-8} \mathrm{~cm}^{3} / \mathrm{s}$ & 27,44 \\
\hline $\mathrm{k}_{8}$ & $\mathrm{Cl}^{-}+\mathrm{Cl}^{+} \rightarrow \mathrm{Cl}+\mathrm{Cl}$ & $k_{8}=5 \times 10^{-8} \mathrm{~cm}^{3} / \mathrm{s}$ & 27,44 \\
\hline $\mathrm{k}_{9}$ & $\mathrm{e}+\mathrm{Cl}^{-} \rightarrow \mathrm{Cl}+2 \mathrm{e}$ & $k_{9}=2.6310^{-8} \exp (-5.37 / \mathrm{Te}) \mathrm{cm}^{3} / \mathrm{s}$ & 27 \\
\hline $\mathrm{k}_{10}$ & $\mathrm{e}+\mathrm{Ar} \rightarrow \mathrm{Ar}^{+}+2 \mathrm{e}$ & $k_{10}=1.2310^{-7} \exp (-18.68 / \mathrm{Te}) \mathrm{cm}^{3} / \mathrm{s}$ & 27,48 \\
\hline $\mathrm{k}_{11}$ & $\mathrm{e}+\mathrm{Ar} \rightarrow \mathrm{Ar}^{*}+2$ & $k_{11}=3.7110^{-8} \exp (-15.06 / \mathrm{Te}) \mathrm{cm}^{3} / \mathrm{s}$ & 27,49 \\
\hline $\mathrm{k}_{12}$ & $\mathrm{e}+\mathrm{Ar}^{*} \rightarrow \mathrm{Ar}^{+}+2 \mathrm{e}$ & $k_{12}=2.0510^{-7} \exp (-4.95 / \mathrm{Te}) \mathrm{cm}^{3} / \mathrm{s}$ & 27,50 \\
\hline $\mathrm{k}_{13}$ & $\mathrm{e}+\mathrm{Ar}^{*} \rightarrow \mathrm{Ar}+\mathrm{e}$ & $k_{13}=2.010^{-9} \mathrm{~cm}^{3} / \mathrm{s}$ & $27,45-47$ \\
\hline $\mathrm{k}_{14}$ & $\mathrm{Ar}^{*}+\mathrm{Ar}^{*} \rightarrow \mathrm{Ar}+\mathrm{Ar}^{+}$ & $k_{14}=6.210^{-10} \mathrm{~cm}^{3} / \mathrm{s}$ & $27,45-47$ \\
\hline $\mathrm{k}_{15}$ & $\mathrm{Ar}^{+}+\mathrm{Cl}^{-} \rightarrow \mathrm{Ar}+\mathrm{Cl}$ & $k_{15}=310^{-8} \mathrm{~cm}^{3} / \mathrm{s}$ & 27 \\
\hline $\mathrm{k}_{16}$ & $\mathrm{Ar}^{*}+\mathrm{Cl}_{2} \rightarrow \mathrm{Ar}+2 \mathrm{Cl}$ & $k_{16}=7110^{-11} \mathrm{~cm}^{3} / \mathrm{s}$ & 52,53 \\
\hline \multicolumn{2}{|c|}{ Surface reactions } & & \\
\hline $\mathrm{k}_{17}$ & $\mathrm{Cl} \rightarrow 1 / 2 \mathrm{Cl}_{2}$ & $k 17=\gamma_{C l} \times D_{C l} / \Lambda^{2} \mathbf{s}$ & 27 \\
\hline $\mathrm{k}_{18}$ & $\mathrm{Cl}^{+} \rightarrow \mathrm{Cl}$ & $k_{18}=2 u_{B, C l^{+}}\left(R^{2} h_{L}+R L h_{R}\right) / R^{2} L s^{-1}$ & 27 \\
\hline $\mathrm{k}_{19}$ & $\mathrm{Cl}_{2}^{+} \rightarrow \mathrm{Cl}_{2}$ & $k_{19}=2 u_{B, C l_{2}^{+}}\left(R^{2} h_{L}+R L h_{R}\right) / R^{2} L s^{-1}$ & 27 \\
\hline $\mathrm{k}_{20}$ & $\mathrm{Ar}^{+} \rightarrow \mathrm{Ar}$ & $k_{20}=2 u_{B, A r^{+}}\left(R^{2} h_{L}+R L h_{R}\right) / R^{2} L s^{-1}$ & 27 \\
\hline $\mathrm{k}_{21}$ & $\mathrm{Ar}^{*} \rightarrow \mathrm{Ar}$ & $k_{21}=D_{A r^{*}} / \Lambda^{2} s^{-1}$ & 27 \\
\hline
\end{tabular}

Table1. Kinetic reactions considered in the mass balance equations. 


\begin{tabular}{|l|l|l|l|}
\hline \multicolumn{2}{|c|}{$\begin{array}{c}\text { Electron impact reactions and volume } \\
\text { reactions }\end{array}$} & Reaction constants, Te (eV) & Ref \\
\hline $\mathrm{k}_{22}$ & $\mathrm{e}+\mathrm{Cl}_{2} \rightarrow \mathrm{Cl}_{2}\left(\mathrm{~b}^{3} \Pi_{\mathrm{u}}\right)+\mathrm{e}$ & $\begin{array}{l}k_{22}=6.1310^{-10} \exp \left(2.74 / T e-6.85 / T e^{2}\right. \\
\left.+3.69 / T e^{3}-0.856 / T e^{4}+0.0711 / T e^{5}\right)\end{array}$ & 27 \\
\hline $\mathrm{k}_{23}$ & $e+\mathrm{Cl}_{2} \rightarrow \mathrm{Cl}_{2}\left({ }^{1} \Pi_{u}\right)+e$ & $k_{23}=3.8010^{-8} \exp (-3.824 / T e)$ & 27 \\
\hline $\mathrm{k}_{24}$ & $\mathrm{e}+\mathrm{Cl}_{2} \rightarrow \mathrm{Cl}_{2}\left({ }^{1} \Pi_{\mathrm{g}}\right)+\mathrm{e}$ & $k_{24}=9.7410^{-9} \exp (-10.71 / T e)$ & 27 \\
\hline $\mathrm{k}_{25}$ & $\mathrm{e}+\mathrm{Cl}_{2} \rightarrow \mathrm{Cl}_{2}\left({ }^{1} \Sigma_{\mathrm{u}}\right)+\mathrm{e}$ & $k_{25}=2.1210^{-9} \exp (-11.16 / T e)$ & 27 \\
\hline $\mathrm{k}_{26}$ & $\mathrm{e}+\mathrm{Cl}_{2} \rightarrow \mathrm{Cl}_{2}+\mathrm{e}(\mathrm{momentum}$ transfert $)$ & $k_{26}=4.4710^{-7} \exp \left(-2.17 / T e+0.362 / T e^{2}\right.$ & 27 \\
\hline $\mathrm{k}_{27}$ & $\mathrm{e}+\mathrm{Cl}{ }_{2} \rightarrow \mathrm{Cl}_{2}+\mathrm{e}(\mathrm{vibrational}$ & $\left.-0.0196 / T e^{3}\right)$ & 27 \\
\hline $\mathrm{k}_{28}$ & $\mathrm{e}+\mathrm{Cl}+\mathrm{Cl} \rightarrow \mathrm{Cl}\left({ }^{3} \mathrm{D}\right)+\mathrm{e}$ & $\left.+1.716 / T e^{3}-0.251 / T e^{4}+0.123 / T e^{5}\right)$ & \\
\hline $\mathrm{k}_{29}$ & $\mathrm{e}+\mathrm{Cl} \rightarrow \mathrm{Cl}\left({ }^{4} \mathrm{D}\right)+\mathrm{e}$ & $k_{28}=1.9910^{-8} \exp (-10.06 / T e)$ & 27,51 \\
\hline $\mathrm{k}_{30}$ & $\mathrm{e}+\mathrm{Cl} \rightarrow \mathrm{Cl}\left({ }^{4} \mathrm{P}\right)+\mathrm{e}$ & $k_{29}=9.2410^{-9} \exp (-11.15 / T e)$ & 27,51 \\
\hline $\mathrm{k}_{31}$ & $\mathrm{e}+\mathrm{Cl} \rightarrow \mathrm{Cl}\left({ }^{4} \mathrm{~S}\right)+\mathrm{e}$ & $k_{30}=1.6010^{-8} \exp (-10.29 / T e)$ & 27 \\
\hline $\mathrm{k}_{32}$ & $\mathrm{e}+\mathrm{Cl} \rightarrow \mathrm{Cl}\left({ }^{5} \mathrm{D}\right)+\mathrm{e}$ & $k_{31}=1.2710^{-8} \exp (-10.97 / T e)$ & 27,51 \\
\hline $\mathrm{k}_{33}$ & $\mathrm{e}+\mathrm{Cl} \rightarrow \mathrm{Cl}\left({ }^{5} \mathrm{P}\right)+\mathrm{e}$ & $k_{32}=5.2210^{-9} \exp (-11.12 / T e)$ & 27,51 \\
\hline
\end{tabular}

Table 2. Kinetic reactions of excitation of both $\mathrm{Cl}_{2}$ and $\mathrm{Cl}$ which are added in the mass balance power equation.

The results of the 0D global plasma model have been compared to electron density and temperature measurements performed in a Sentech SI 500 ICP etch system used to etch III-V materials, and customized to integrate electrical and optical diagnostics [41, 42]. The ICP source consists of a planar antenna with an $\mathrm{Al}_{2} \mathrm{O}_{3}$ coupling window. The reactor chamber is made of unanodised aluminum. The height from coupling window to electrode surface is of $\sim 130 \mathrm{~mm}$ and the internal chamber diameter is of $350 \mathrm{~mm}$. A c- $\mathrm{Al}_{2} \mathrm{O}_{3}$ wafer was used as the (un-biased) electrode coverplate during measurements. Details of the experimental procedure can be found in [43]. The RF-compensated Langmuir probe was positioned $\sim 35 \mathrm{~mm}$ above the electrode surface [and $130 \mathrm{~mm}$ away from the reactor center] during the measurements. The surface recombination coefficient of $\mathrm{Cl}$ atoms $\gamma_{\mathrm{Cl}}$ in the reactor was estimated using the PIF method [42] and was found to be lie in the range of 0.03-0.05 for ICP powers in the range of $150 \mathrm{~W}-800 \mathrm{~W}$, at $10 \mathrm{mT}$ pressure. Except for the study of the effect of the $\gamma_{\mathrm{Cl}}$ on the $\mathrm{Cl}_{2}$-Ar kinetic plasma properties (figures 6-9), the simulations are carried out for $\gamma_{\mathrm{Cl}}=0.04$. 
Figure 1 shows the electron density evolution with power for different pressure and pressure values. For different gas pressures, electron density increases with power because of the increase of the ionisation rate. At low power [ne] decreases with pressure. This characterises the electronegative plasma. However, over 400 watt, the electron density increases with the pressure. We can observe that the electronegativity of $\mathrm{Cl}_{2} / \mathrm{Ar}$ represented by the ratio $\left[\mathrm{Cl}^{-}\right] /\left[\mathrm{n}_{\mathrm{e}}\right]$ decreases with RF power (figure 2). $\left[\mathrm{Cl}^{-}\right] /\left[n_{e}\right]$ is sensitive to the pressure for $\mathrm{P}_{\mathrm{rf}}$ lower than 400 watt Beyond this value, $\left[\mathrm{Cl}^{-}\right] /\left[\mathrm{n}_{\mathrm{e}}\right]$ becomes less sensitive to the pressure variations.

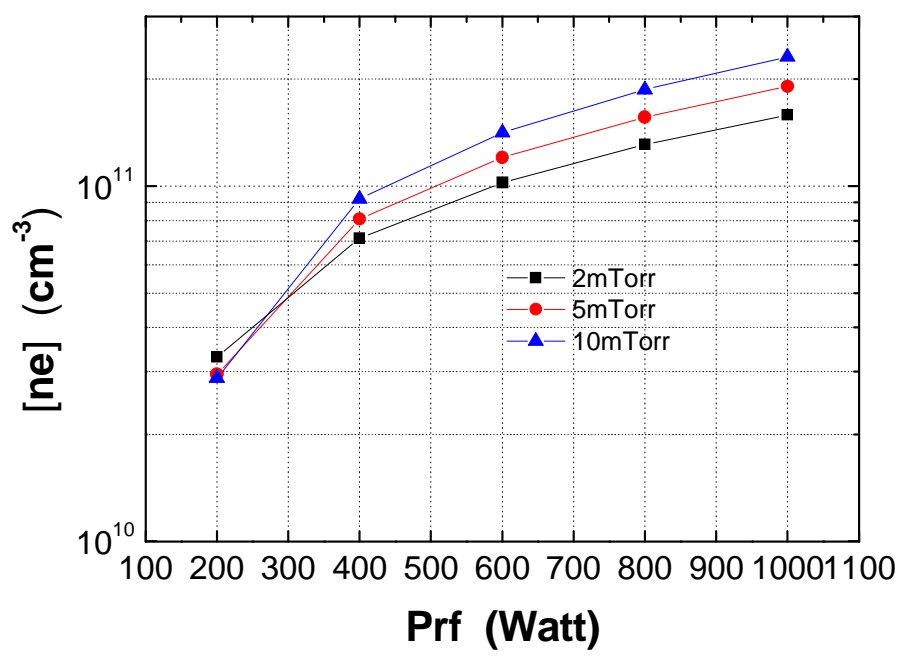

Figure 1. Variation of electron density with power for pressure ranging trom 2 to 10 mtorr, $\mathrm{Q}\left(\mathrm{Cl}_{2} / \mathrm{Ar}\right.$

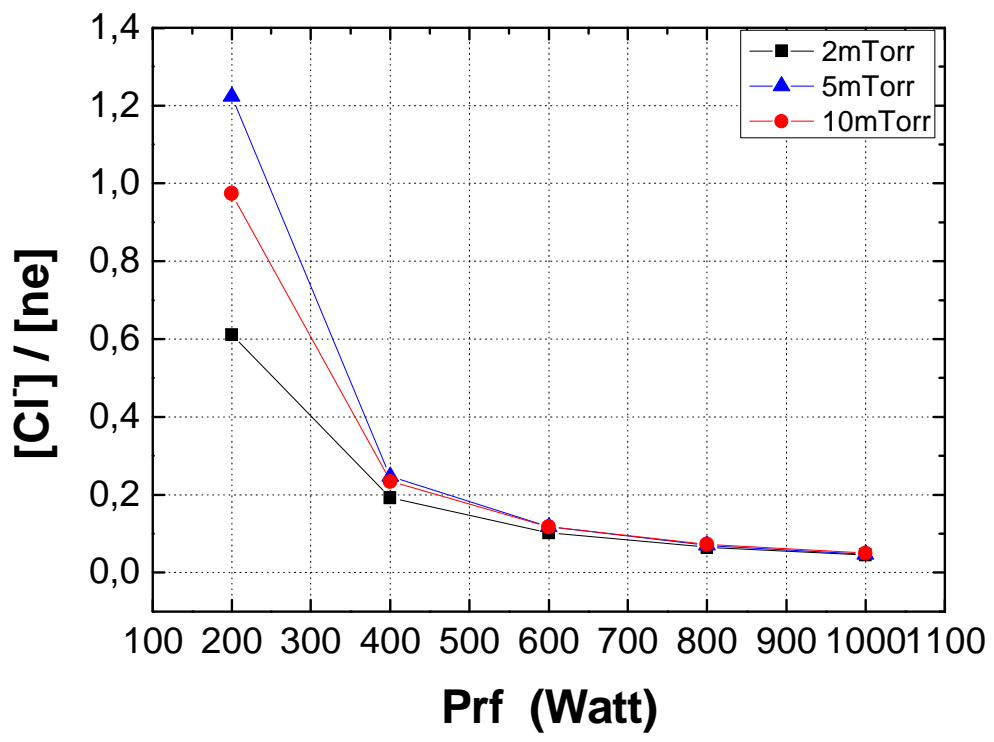

Figure 2. Variation of $\mathrm{Cl}^{-}$ion to electron density ratio with power for pressure ranging from 2 to 10 mtorr, $\mathrm{Q}\left(\mathrm{Cl}_{2} / \mathrm{Ar}\right)=10: 10 \mathrm{sccm}$. 
The variation of the electron temperature for different values of pressure is presented in figure 3. For the pressure ranging from 2 to 10 mtorr, $T_{e}$ decreases as a function of power for Prf $<400 \mathrm{Watt}$. In this power interval, the augmentation of power has more effect in the production of electrons by ionization processes (figure 1) leading to the diminution of electron energy. However, for a high power values one fraction of power causes the acceleration of electrons leading to the increase of their average energy (electron temperature).

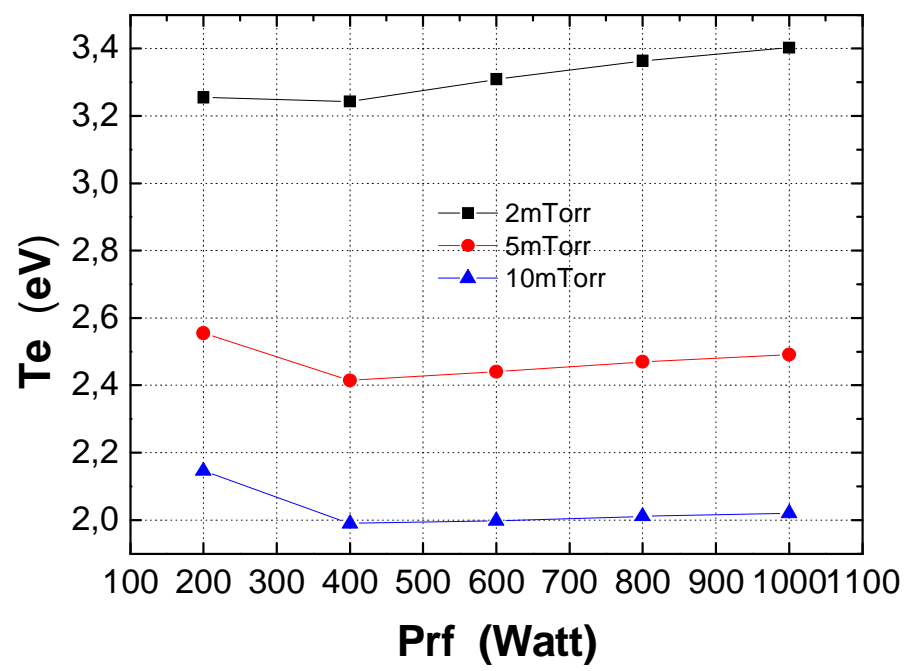

Figure 3. Electron temperature variation with power for pressure ranging from 2 to 10 mtorr, $\mathrm{Q}\left(\mathrm{Cl}_{2} / \mathrm{Ar}\right)=10: 10 \mathrm{sccm}$.

Figure 4 shows the variation of the dissociation percentage of $\mathrm{Cl}_{2}$ as a function of power and pressure. It is calculated as: $\operatorname{dis}(\%)=\frac{x_{C l 2} N_{o}-\left[C l_{2}\right]}{x C l_{2} N_{o}} \times 100$, where $x_{C l 2}$ is the fraction of $\mathrm{Cl}_{2}, N_{o}$ is the initial total concentration in the reactor which is determined as a function of the pressure $p$ using parfait gaz law: $N_{o}\left(\mathrm{~cm}^{-3}\right)=3.53910^{16} p(t o r r)$. At low power, we observe a high variation of the $\mathrm{Cl}_{2}$ dissociation rate. Over $600 \mathrm{~W}$ att of pressure, such variation becomes low. Noting that the dissociation rate of $\mathrm{Cl}_{2}$ decreases with the pressure [32-33]. In addition to ions, determination of atomic chlorine density as a function of the operating parameters is useful to determine the $\mathrm{Cl}$ flux in the etching process. Such parameter is introduced (see below) as input data in the etching model. 


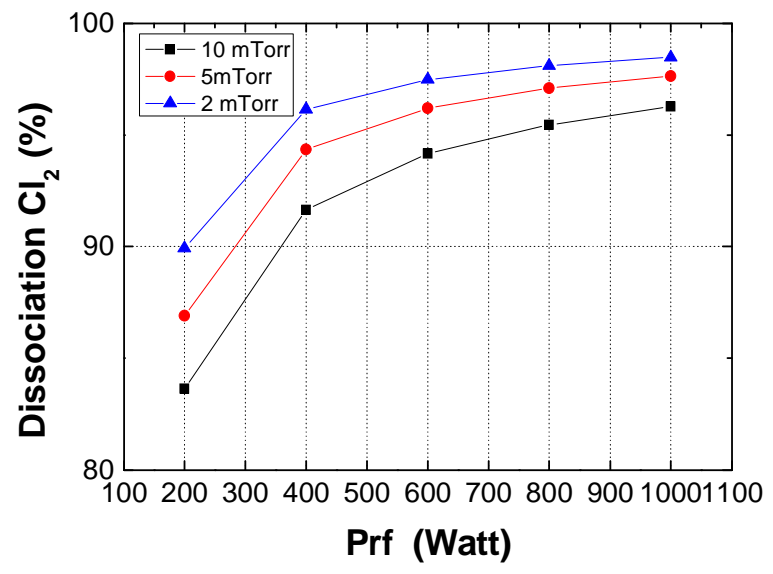

Figure 4. Dissociation percentage of $\mathrm{Cl}_{2}$ as a function of power and pressure, $\mathrm{Q}\left(\mathrm{Cl}_{2} / \mathrm{Ar}\right)=10: 10 \mathrm{sccm}$.

In figure 5, we present, the variation of the chlorine density $[\mathrm{Cl}]$ with power for pressure ranging from 2 to 10 mtorr. The increase of such parameter with power is due to the increase of the dissociation rate of molecular chlorine (figure 4).

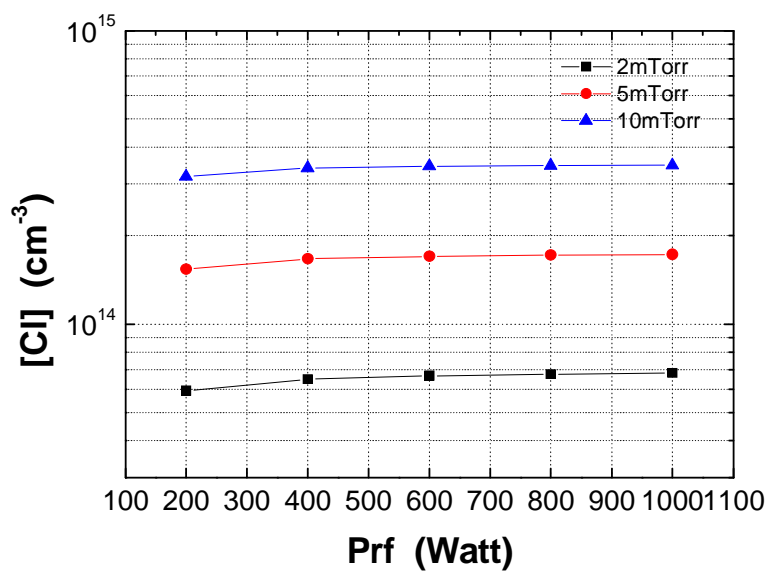

Figure 5. Atomic chlorine density variation with power, $\mathrm{Q}\left(\mathrm{Cl}_{2} / \mathrm{Ar}\right)=10: 10 \mathrm{sccm}$.

In low pressure ICP, the role of the plasma surface interaction is very important in the transport study of both charged and neutral species created in the plasma. In our 0D kinetic model, the loss term of atomic chlorine by diffusion mechanism is introduced using Chantry theory [29]. This term is assumed proportional to the recombination coefficient $\gamma_{\mathrm{Cl}}$ on the surface (equation 3). The impact of $\gamma_{\mathrm{Cl}}$ (reaction 17) on the transport phenomena is done in order to understand the mechanisms of the neutral interactions on the surface and their effects on the plasma discharge behaviour. Figure 6 shows the effect of the variation of the recombination coefficient $\gamma_{\mathrm{Cl}}$ on the electron density variation for 2 and 5 mtorr of pressure, 1000 watt of RF power and $10 \mathrm{sccm}$ for both $\mathrm{Cl}_{2}$ and Ar flow rates. Two regimes can be identified: for $\gamma_{\mathrm{Cl}}$ lower 
than 0.01 , we observe a slow diminution of [ne] with $\gamma_{\mathrm{Cl}}$; from 0.01 to 1 , the diminution of [ne] with $\gamma_{\mathrm{Cl}}$ becomes very fast. In the case of the $\left[\mathrm{Cl}^{-}\right]$evolution with $\gamma_{\mathrm{Cl}}$ (figure $7-\mathrm{a}$ ), we observe a fast increase of $\left[\mathrm{Cl}^{-}\right]$for $\gamma_{\mathrm{Cl}}$ from 0.001 to 0.1 . Beyond 0.1 a stability of $\left[\mathrm{Cl}^{-}\right]$is observed by varying $\gamma_{\mathrm{Cl}}$. On the other hand, for $\gamma_{\mathrm{Cl}}$ less than $10^{-2}$ electron density [ $\mathrm{n}_{\mathrm{e}}$ ] is less sensitive to the pressure. This tendency changes when $\gamma_{\mathrm{Cl}}$ takes values up to $10^{-2}$. We can also observe that $\gamma_{\mathrm{Cl}}$ has an important effect on the electronegativity of $\mathrm{Cl}_{2} / \mathrm{Ar}$ plasma discharge. Indeed, figure 7-b shows that in the operating conditions mentioned above $\left(\mathrm{P}_{\mathrm{RF}}=1000\right.$ watt and $\left.\mathrm{Q}_{\mathrm{Cl} 2 / \mathrm{Ar}}=10: 10 \mathrm{sccm}\right), \mathrm{Cl}_{2} / \mathrm{Ar}$ plasma is all the more electronegative than $\gamma_{\mathrm{Cl}}$ is higher because of the increase of the $\left[\mathrm{Cl}_{2}\right]$ (figure8) and consequently the attachment phenomena leading to the augmentation of the $\left[\mathrm{Cl}^{-}\right]$.

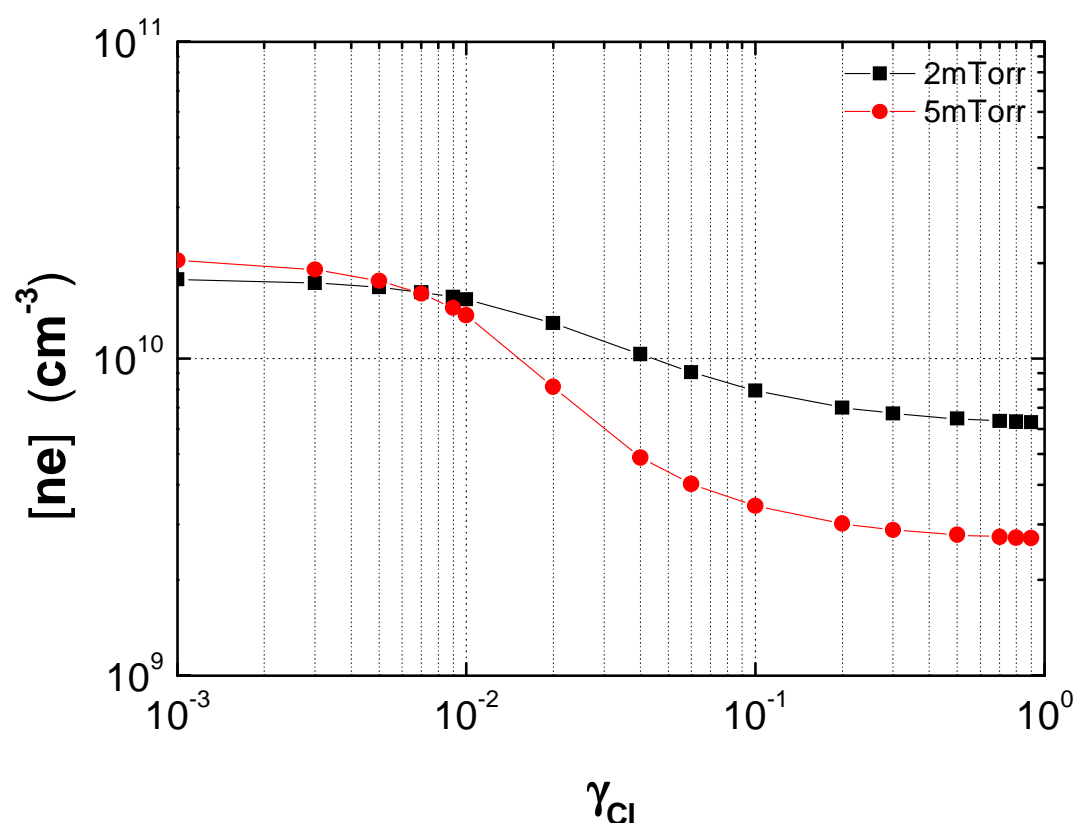

Figure 6. Effect of the recombination coefficient of chlorine on the electron density variation. 

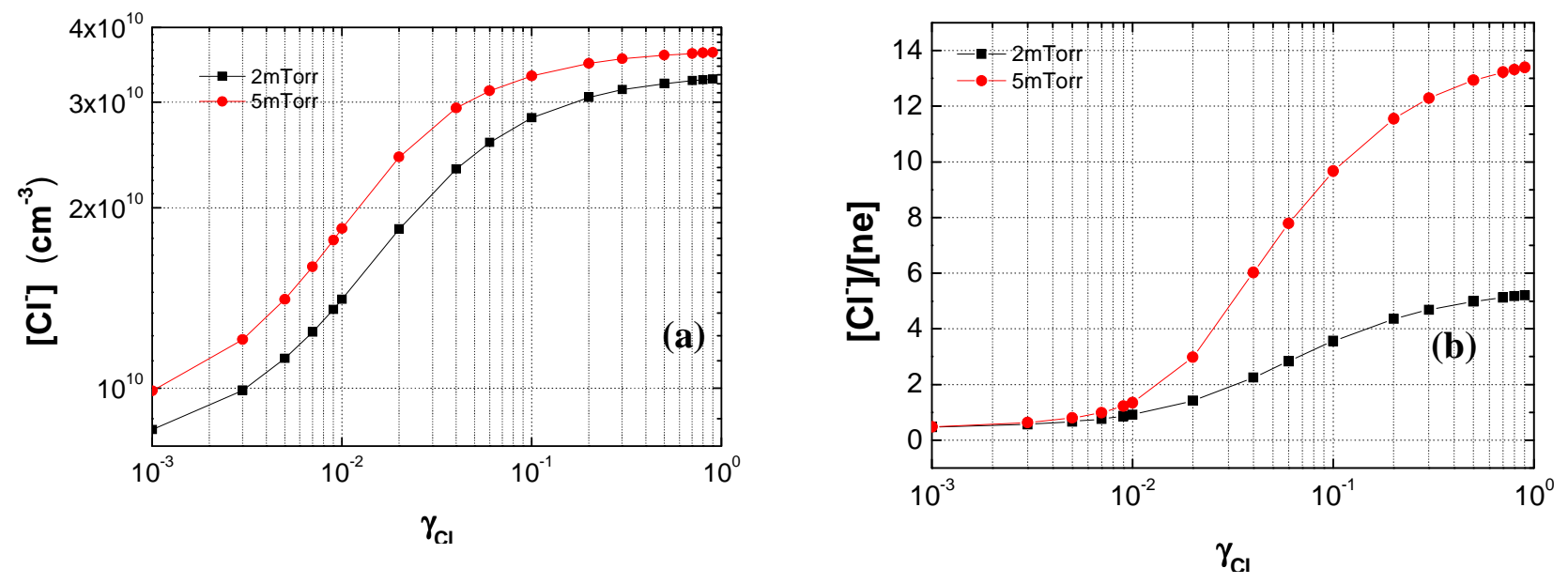

Figure 7. (a), (b): $\left[\mathrm{Cl}^{-}\right]$and $\left[\mathrm{Cl}^{-}\right] /[$ne] evolutions with recombination coefficient of $\mathrm{Cl}$.

Figure 8 presents the $\mathrm{Cl}_{2}$ density variation as a function $\gamma_{\mathrm{Cl}}$. For $\gamma_{\mathrm{Cl}}$ lower than $0.2,\left[\mathrm{Cl}_{2}\right]$ increases by increasing $\gamma_{\mathrm{Cl}}$. Over 0.2 , a low increase of $\left[\mathrm{Cl}_{2}\right]$ is observed. Noting that for both pressures 2 and 5 mTorr, $\left[\mathrm{Cl}_{2}\right]$ is lower than that the initial $\mathrm{Cl}_{2}$ density $\left[\mathrm{Cl}_{2}\right]_{\mathrm{o}}$ for $\gamma_{\mathrm{Cl}}=0.04$ because of the high $\mathrm{Cl}_{2}$ dissociation rate (figure 4). Furthermore, high values of atomic chlorine are observed when $\gamma_{\mathrm{Cl}}$ is less than 0.01 due to the high dissociation of $\mathrm{Cl}_{2}$. Beyond this value; we observe a decrease of $[\mathrm{Cl}]$ (figure 9) due to the increase of the loss term on the surface of the $\mathrm{Cl}$ (reaction 17). 


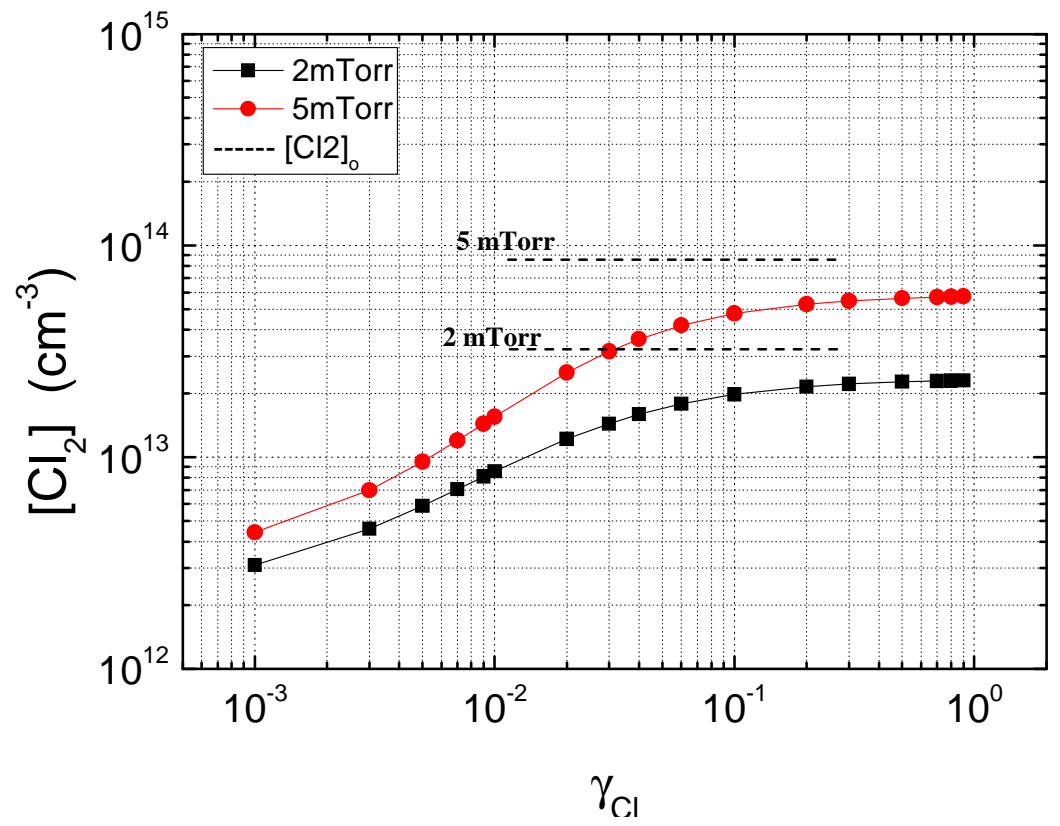

Figure 8. Effect of the recombination coefficient of chlorine on the molecular chlorine density variation. $\left[\mathrm{Cl}_{2}\right]_{\mathrm{o}}$ is the chlorine initial density when the plasma is off.

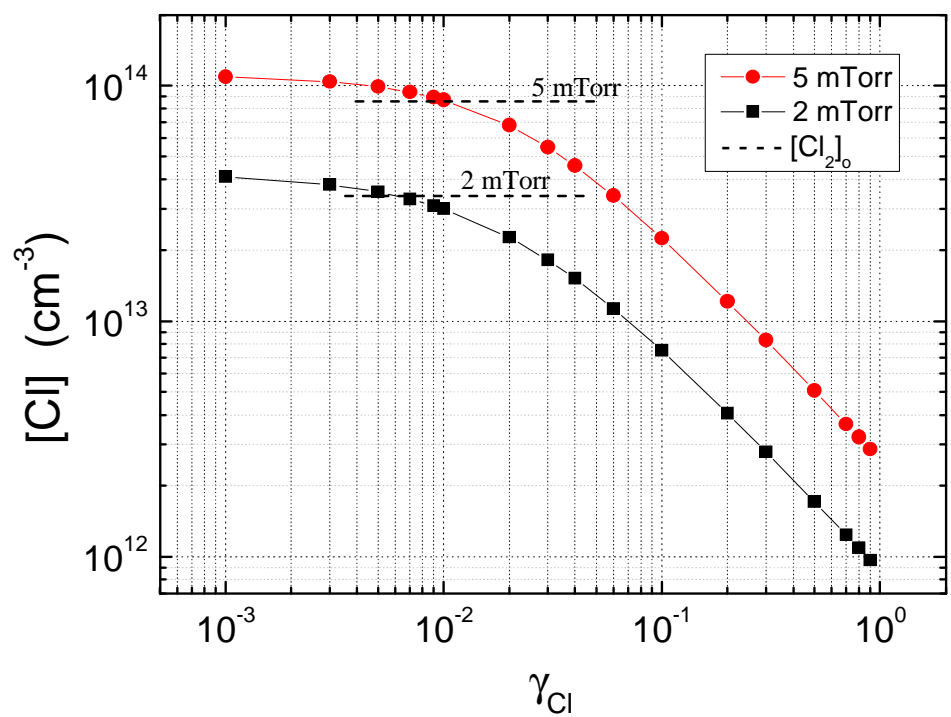

Figure 9 Effect of the recombination coefficient of chlorine on the atomic chlorine density variation. $\left[\mathrm{Cl}_{2}\right]_{\mathrm{o}}$ is the chlorine initial density when the plasma is off. 
Figure 10 presents the comparison between the simulation and the experiment concerning the electron density and the electron temperature as a function of RF power for 2 mtorr of pressure and $\mathrm{Q}_{\mathrm{Cl} 2 / \mathrm{Ar}}=16: 4 \mathrm{sccm}$. For electron density, a less difference is obtained between the simulation and the experiment (figure 10-a). For the electron temperature, a small deviation of the simulated curve from the experiment is observed which is still lesser than $1 \mathrm{eV}$. However, a good tendency is obtained. The average electron density is expected to be smaller (i) due to its radial decrease within the diffusion chamber, from the centre to the wall, as observed in probe measurements; (ii) due to its axial decrease, from the source to the substrate holder.
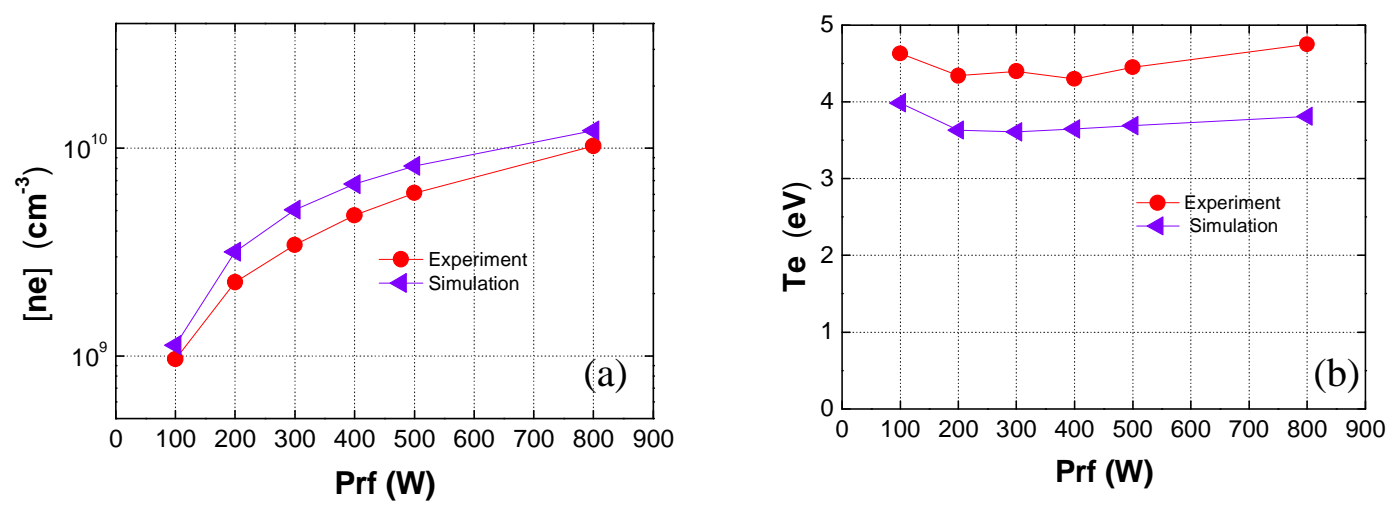

Figure 10. Comparison between the simulation and the experiment. (a) electron density variation with power, (b): electron temperature with power, $\mathrm{p}=2 \mathrm{mtorr}, \mathrm{Q}_{\mathrm{Cl} / \mathrm{Ar}}=16: 4 \mathrm{sccm}$.

\section{Etching model}

The model of InP etching by $\mathrm{Cl}_{2} / \mathrm{Ar}$ plasma is based on the Monte-Carlo approach. Contrary to the dynamic molecular approach [34-35], the Monte-Carlo kinetic approach permits to use a large etched surface. This method is already used by representing the initial etched InP material under a simple cubic network which the indium and phosphor are randomly placed [36] to respect the amorphous structure in the shallow layers existing near the surface. The transformation from monocrystalline to amorphous structure in the shallow layers is mainly caused by the ion bombardment [36].

In our new version of etching model, we consider the realistic representation of $\mathrm{InP}$ etched material based on the zinc-blende structures. Figure 11 presents the initial etched InP where $\mathrm{N}_{\mathrm{x}}$, $\mathrm{N}_{\mathrm{y}}$ and $\mathrm{N}_{\mathrm{z}}$ represent the lattice number along $\mathrm{x}, \mathrm{y}$ and $\mathrm{z}$ directions respectively.

Two reactive species are taken into account in our InP etching model, atomic chlorine and ion. The main steps of our etching module are summarized as follow: We start by giving the $\mathrm{Cl}$ and ion fluxes which are calculated with the global kinetic model as a function of the operating conditions ( $\mathrm{RF}$ power, pressure, $\mathrm{Cl}_{2} / \mathrm{Ar}$ flow rates..). By generating a random number, we select one of the considered precursors. If the neutral species is selected $(\mathrm{Cl}$ in our case) then, two random numbers are generated to select its random position $(\mathrm{x}, \mathrm{y})$. the $\mathrm{z}$ position is chosen on the non occupied plane over the InP surface. The neutral particle is moved into the surface InP sites until encountered occupied nearest neighbour $\mathrm{ACl}_{\mathrm{x}}$ sites $(\mathrm{A}=\mathrm{In}$ or $\mathrm{P}$ and $\mathrm{x}=0-3)$ in the $1 / 8$ of the InP lattice (sub-cub) of the zinc blende structure. Inside this sub-cube, $\mathrm{Cl}$ can adsorb, desorb or jump to one of the nearest neighbour sub-cube. The adsorbed site $\mathrm{ACl}_{\mathrm{x}+1}$ can chemically desorb 
(chemical etching). When the ion is selected, the sputtered indium and phosphorous sites are randomly selected as a function of their sputtering yields.

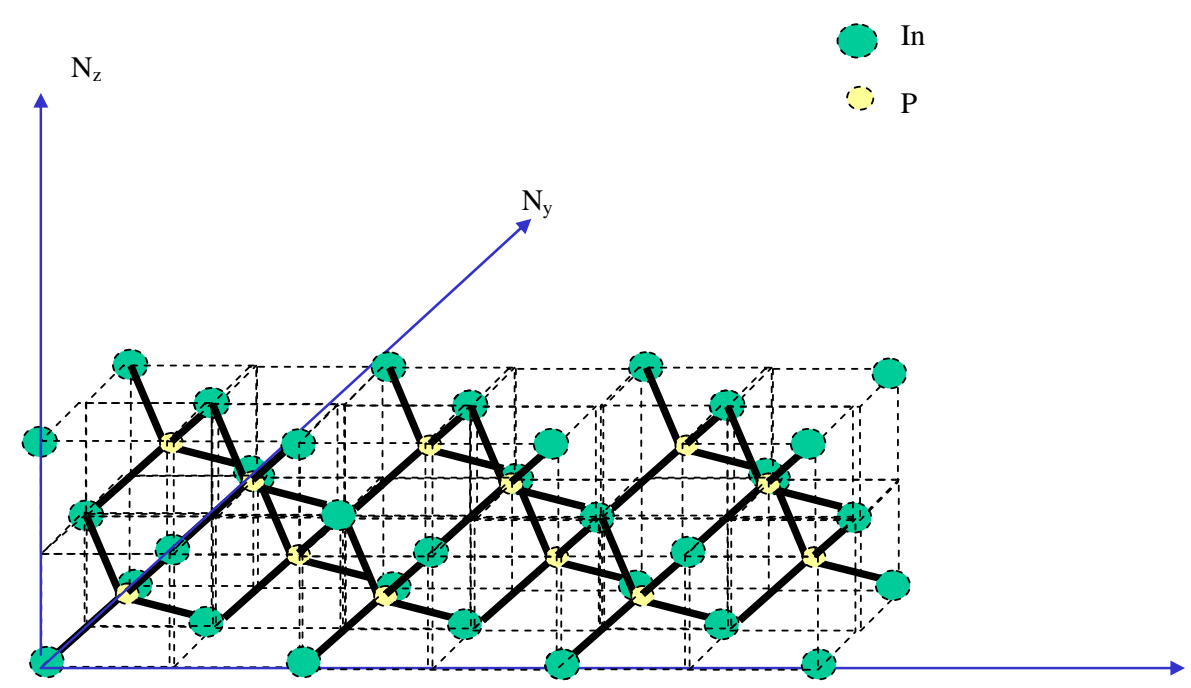

Figure 11. Initial representation of InP (zinc blende structure)

\subsection{Precursor transport}

Knowing the neutral and ion fluxes $\left(\Gamma_{i o n+}=\Gamma_{A r+}+\Gamma_{C_{2}^{+}}+\Gamma_{C^{+}}\right)$calculated from the global kinetic model, we define time step $\Delta \mathrm{t}$ corresponding to average time between two incident etchant precursors:

$$
\Delta t=\frac{1}{S \cdot \Gamma_{T}}
$$

where $\Gamma_{\mathrm{T}}$ is the total flux of precursors and $\mathrm{S}$ is the InP etched surface. To determine which precursor $\mathrm{j}(\mathrm{Cl}$ or ion) is selected, a random number $\mathrm{R}$ is generated and is compared to the flux fraction $X_{j}=\frac{\Gamma_{j}}{\Gamma_{T}} . \mathrm{Cl}$ is selected for $R \leq X_{C l}$ and ion for $X_{C l}<R \leq 1$.

\subsection{Chlorine surface interaction}

The probability of each process is defined as a function of surface energies associated to each process by considering Arrhenius law:

$$
P_{i, j}=\frac{\exp \left(-\frac{E_{i, j}}{K T_{s}}\right)}{\exp \left(-\frac{E_{a d s, j}}{K T_{s}}\right)+\exp \left(-\frac{E_{d e s, j}}{K T_{s}}\right)+\exp \left(-\frac{E_{\text {mig,j }}}{K T_{s}}\right)}
$$

where $E_{i, j}$ is the surface energy associated to the process $i$ (i=adsorption, desorption, migration) on the $\mathrm{j}^{\text {th }}$ site $\left(\mathrm{j}=\mathrm{ACl}_{\mathrm{x}}, \mathrm{x}=0-2\right)$. Chemical etching process may occur after the 
formation of the $\mathrm{ACl}_{\mathrm{x}+1}$ by adsorption of $\mathrm{Cl}$ on $\mathrm{ACl}_{\mathrm{x}}$. The chemical etching probability is defined as:

$$
P_{\text {chem }, j}=p_{o} \cdot \exp \left(-\frac{E_{\text {etch }, j}}{K \cdot T s}\right)
$$

where $E_{\text {etch, } j}$ is the desorption energy of the $\mathrm{j}^{\text {th }}$ species $\left(\mathrm{j}=\mathrm{ACl}_{\mathrm{x}}, \mathrm{x}=1-3\right), p_{o}$ is a constant and $\mathrm{T}_{\mathrm{s}}$ is the surface temperature.

The main difficulty to develop the plasma surface interaction is the lack of the data base concerning the surface parameters such as adsorption and desorption energies of all the formed sites on the etched surface. Table 3 presents the surface kinetic of the etched InP under $\mathrm{Cl}$ and ion fluxes and their associated surface energies. These are calculated by Jenichen et al [37] using molecular models for local surface structures and the density functional method. The migration energy of $\mathrm{Cl}$ is assumed independent of the $\mathrm{ACl}_{\mathrm{x}}$ neighbour sites and it is estimated at $1.3 \mathrm{eV}$.

\subsection{Ion InP sputtering model}

The energetic ion transport study in InP substrate volume is very complex and requires introducing the linear cascade regime theory [38]. It is not easy to combine our neutral kinetic Monte-Carlo approach with linear cascade regime. Nevertheless, a semi-empirical expression giving the sputtering yield versus the ion energy is used [39]:

$$
Y\left(\alpha, E_{i o n}\right)=\alpha \cdot B \cdot\left(\sqrt{E_{i o n}}-\sqrt{E_{t h}}\right)
$$

where $\alpha$ is the modulation coefficient associated to the site $\mathrm{ACl}_{\mathrm{x}}(\mathrm{x}=0-3)$. For $\mathrm{x}=0, \alpha=1$ while it

\begin{tabular}{|c|c|c|c|c|c|c|}
\hline \multicolumn{7}{|c|}{ Neutral (Cl) InP surface interactions } \\
\hline $\begin{array}{l}\text { Surface kinetic } \\
\text { reactions }\end{array}$ & $\begin{array}{l}\text { Adsorption } \\
\text { energy (eV) }\end{array}$ & \multicolumn{2}{|c|}{$\begin{array}{l}\text { Desorption } \\
\text { energy }(\mathrm{eV})\end{array}$} & \multicolumn{2}{|c|}{$\begin{array}{l}\text { Etching energy } \\
(\mathrm{eV})\end{array}$} & $\begin{array}{l}\text { Migration } \\
\text { energy }(\mathrm{eV})\end{array}$ \\
\hline $\mathrm{Cl}+\mathrm{In} \rightarrow \mathrm{InCl}$ & 1.2 & \multicolumn{2}{|c|}{1.7} & \multicolumn{2}{|l|}{1.5} & 1.3 \\
\hline $\mathrm{Cl}+\mathrm{InCl} \rightarrow \mathrm{InCl}_{2}$ & 2.8 & \multicolumn{2}{|l|}{1.7} & \multicolumn{2}{|l|}{2.79} & 1.3 \\
\hline $\mathrm{Cl}+\mathrm{InCl}_{2} \rightarrow \mathrm{InCl}_{3}$ & 0.473 & \multicolumn{2}{|l|}{1.7} & \multicolumn{2}{|l|}{0.35} & 1.3 \\
\hline $\mathrm{Cl}+\mathbf{P} \rightarrow \mathbf{P C l}$ & 2. & \multicolumn{2}{|l|}{1.7} & \multicolumn{2}{|l|}{2.48} & 1.3 \\
\hline $\mathrm{Cl}+\mathrm{PCl} \rightarrow \mathrm{PCl}_{2}$ & 1.2 & \multicolumn{2}{|l|}{1.7} & \multicolumn{2}{|l|}{1.14} & 1.3 \\
\hline $\mathrm{Cl}+\mathrm{PCl}_{2} \rightarrow \mathrm{InCl}_{3}$ & 1.2 & \multicolumn{2}{|l|}{1.7} & \multicolumn{2}{|l|}{0.057} & 1.3 \\
\hline \multicolumn{7}{|c|}{ Ion sputtering mechanisms } \\
\hline & \multicolumn{2}{|l|}{$\mathrm{B}\left(\mathrm{eV}^{-1 / 2}\right)$} & \multicolumn{2}{|c|}{ Eth(eV) } & \multicolumn{2}{|c|}{$\alpha$} \\
\hline ion + In $\rightarrow$ In & \multicolumn{2}{|l|}{0.02} & \multicolumn{2}{|c|}{$\mathbf{0}$} & \multicolumn{2}{|c|}{1} \\
\hline ion+ InCl $\rightarrow$ InCl & \multicolumn{2}{|l|}{0.02} & \multicolumn{2}{|l|}{$\mathbf{0}$} & \multicolumn{2}{|l|}{3} \\
\hline ion $+\mathrm{InCl}_{2} \rightarrow \mathrm{InCl}_{2}$ & \multicolumn{2}{|l|}{0.02} & \multicolumn{2}{|l|}{$\mathbf{0}$} & \multicolumn{2}{|c|}{3} \\
\hline ion $+\mathrm{InCl}_{3} \rightarrow \mathrm{InCl}_{3}$ & \multicolumn{2}{|l|}{0.02} & \multicolumn{2}{|l|}{$\mathbf{0}$} & \multicolumn{2}{|l|}{7} \\
\hline ion $+\mathbf{P} \rightarrow \mathbf{P}$ & \multicolumn{2}{|l|}{0.011} & \multicolumn{2}{|l|}{$\mathbf{0}$} & \multicolumn{2}{|c|}{1} \\
\hline ion $+\mathrm{PCl} \rightarrow \mathrm{PCl}$ & \multicolumn{2}{|l|}{0.011} & \multicolumn{2}{|l|}{$\mathbf{0}$} & \multicolumn{2}{|c|}{5} \\
\hline ion $+\mathbf{P C l}_{2} \rightarrow \mathrm{InCl}_{2}$ & 0.011 & & $\mathbf{0}$ & & 5 & \\
\hline ion $+\mathrm{PCl}_{2} \rightarrow \mathrm{InCl}_{2}$ & 0.011 & & O & & 10 & \\
\hline
\end{tabular}
is higher than 1 for $\mathrm{x}>0$. $\mathrm{B}$ is estimated using TRIM code [38] (table 3).

Table 3. Surface parameters of etched InP under neutral particles (chlorine) and ions . 


\subsection{Simulation results}

One of the advantages of our etching model is to give information about the structural properties of the etched InP in the early stage. Figure 12 presents the etch rate evolution versus time for RF power of 1000 watts, 2 mtorr of pressure, $100 \mathrm{~V}$ of $\mathrm{V}_{\mathrm{DC}}, 10: 10 \mathrm{sccm}$ of the $\mathrm{Cl}_{2} / \mathrm{Ar}$ flow rates and $180{ }^{\circ} \mathrm{C}$ of substrate temperature. The calculation of the $\mathrm{Cl}$ and ion fluxes from the global kinetic model gives $\Gamma_{\mathrm{Cl}}=510^{17} \mathrm{~cm}^{-2} \mathrm{~s}^{-1}$ and $\Gamma_{\text {iont }}=5.410^{16} \mathrm{~cm}^{-2} \mathrm{~s}^{-1}$.

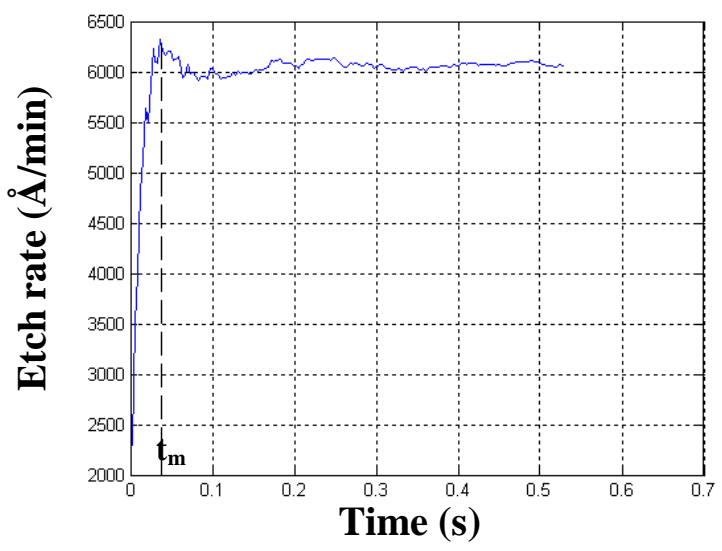

Figure 12. Etching rate evolution with etch time at the early stage

For $\mathrm{t}<\mathrm{t}_{\mathrm{m}}\left(\mathrm{t}_{\mathrm{m}} \sim 0.04 \mathrm{~s}\right)$, the etch rate increases with time until it reaches a maximum value. Beyond this value, a steady state regime is observed. The increase of the etch rate with time for $\mathrm{t}<\mathrm{t}_{\mathrm{m}}$ is due to the increase of the coverage rate on the adsorbed chloride sites on the surface (figure 13) leading to the increase of the ion neutral synergy of etching. Beyond $t_{m}$, we observe a stability of this coverage rate (figure 13) leading to the stability of the etch rate. 


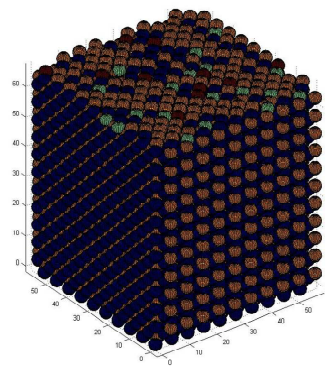

$10^{-2} \mathrm{~s}$

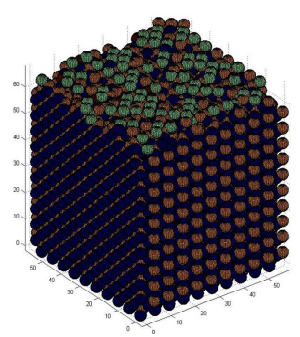

$310^{-2} s$

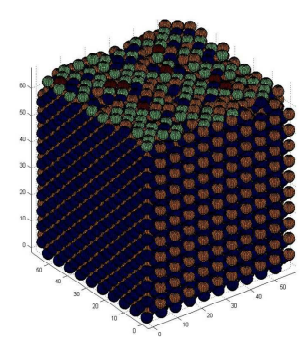

$210^{-2} s$

$\mathrm{In}$
$\mathrm{P}$
$\mathrm{InCl}_{\mathrm{x}}$

$\mathrm{PCl}_{\mathrm{x}}$

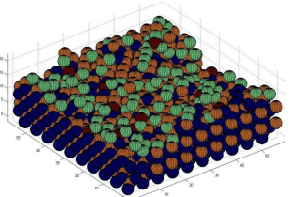

$510^{-1} \mathrm{~s}$

Figure 13. Chemical composition evolution of the etched surface versus etch time

Figure 14 shows the variation of the Roughness rate evolution with time. Contrary to the etch rate that begins to stabilize at $\mathrm{t}=0.04 \mathrm{~s}$, the RMS is stabilized at $0.4 \mathrm{~s}$. The control of the roughness becomes an important challenge as the miniaturization of the optoelectronic devices progress. So it is important to know more about the mechanisms of the RMS evolution versus the operating conditions.

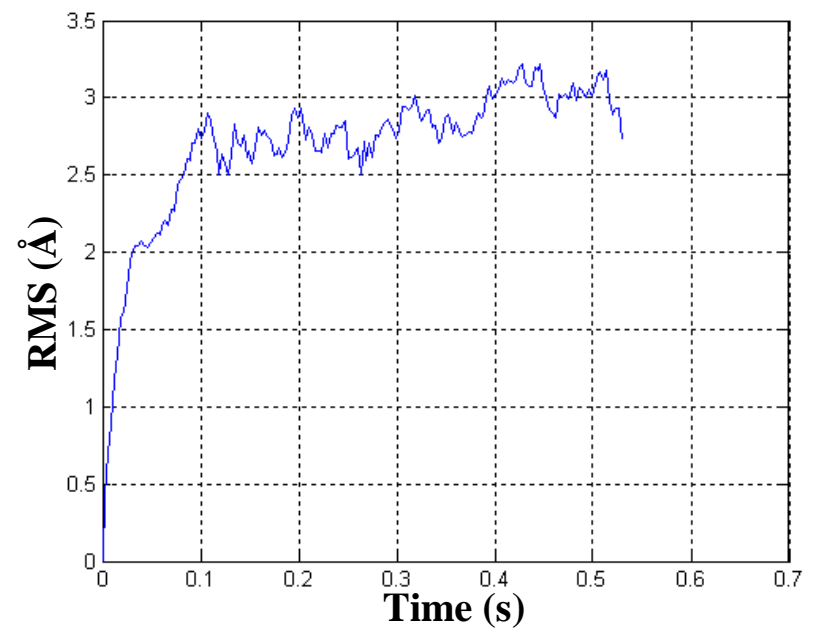

Figure 14. Variation of RMS versus etch time. 
Figure 15 presents relative RMS variation versus the pressure for $\mathrm{P}_{\mathrm{RF}}=1000$ watts, $\mathrm{V}_{\mathrm{DC}}=100 \mathrm{~V}, \mathrm{Q}_{\mathrm{Cl} 2 / \mathrm{Ar}}=10 / 10 \mathrm{sccm}$ and $\mathrm{T}_{\mathrm{S}}=180{ }^{\circ} \mathrm{C}$. The relative RMS is defined as:

$$
R R M S(\%)=\frac{R M S}{t_{e c h}} \times 100
$$

where $t_{\text {ech }}$ is the InP etched thickness. RMS and $t_{\text {ech }}$ are calcundlated at $\mathrm{t}=0.5 \mathrm{~s}$. The simulation result shows a diminution of the RRMS with the pressure. It varies from $12.8 \%$ for $\mathrm{p}=2$ mtorr to $4.8 \%$ for $\mathrm{p}=10$ mtorr. This can be explained by the diminution of the ion to chlorine flux ratio (figure 16). Indeed, $\Gamma_{\text {ion }} / \Gamma_{\mathrm{Cl}}$ passes from 0.1 for 2 mtorr to 0.025 for 10 mtorr. The increase of the ion bombardment is a source of the etched surface roughness enhancement.

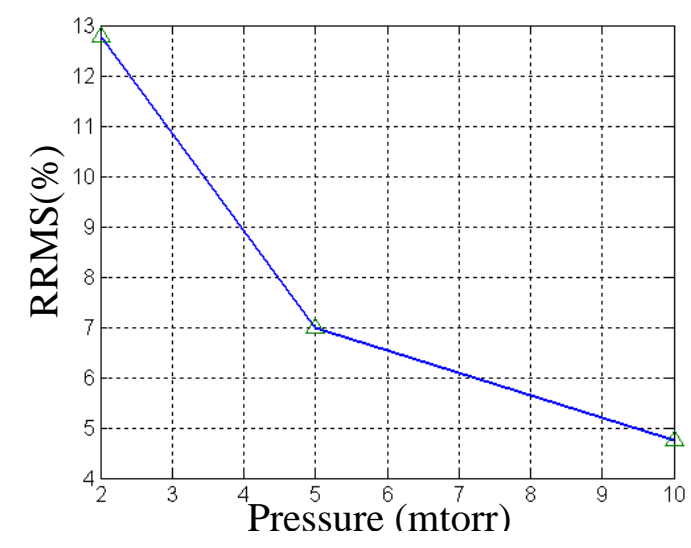

Figure 15. Variation of the RRMS with pressure

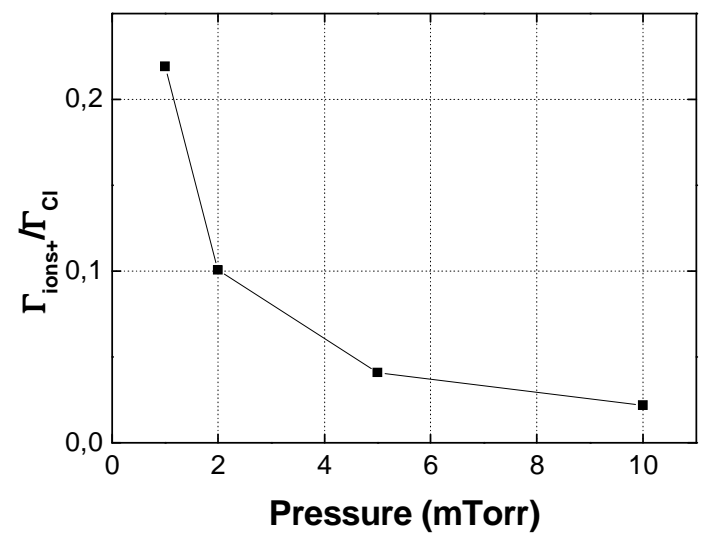

Figure 16. Ion to chlorine flux ratio versus pressure. 


\section{Conclusion}

Gas phase kinetic model for $\mathrm{Cl}_{2}$ - $\mathrm{Ar}$ ICP plasma discharge has been developed to investigate the plasma characteristics under operating conditions. The model based on the OD approach allows to predict average densities of species produced in $\mathrm{Cl}_{2} / \mathrm{Ar}$ plasma discharge. Simulation results show that the electronegativity of $\mathrm{Cl}_{2}$ - Ar plasma measured by calculating $\left[\mathrm{Cl}^{-}\right] /[\mathrm{ne}]$ decreases with increasing RF power and decreasing pressure. A minimum value of the electron temperature is observed at 400 watt. Furthermore, we have analyzed the effect of the surface recombination coefficient of atomic chlorine on the plasma neutral and charged species transport phenomena. The simulation results show that in low pressure, the surface parameters play an important role in the transport phenomena of charged and neutral species created in $\mathrm{Cl}_{2} / \mathrm{Ar}$ plasma discharge. A satisfactory agreement between the simulation and the experiment concerning the electron density and the electron temperature evolutions with power are obtained for recombination coefficient of atomic chlorine $\gamma_{\mathrm{Cl}}$ fixed at 0.04 . The later is consistent with that estimated experimentally.

On the other hand, a preliminary study concerning the impact of the operation conditions on the etched surface properties is presented. Our attention is particularly paid on the early stage study of the plasma surface interactions where we showed the effect of the correlation between of the RRMS and ion to neutral flux ratio evolutions with pressure.

\section{Acknowledgments:}

The authors thank Dr. Sophie Bouchoule and Dr. Lina Gatilova of LPN-CNRS for the electron density and temperature measurements. Part of this work has been supported by Agence Nationale de la Recherche in the frame of ANR-09-BLAN-0019 INCLINE project. 


\section{References}

[1] P. Strasser, R. Wüest, and F. Robin, A. Forchel, J. Vac. Sci. Technol. B 25, 387-393 (2007).

[2] S. Samukawa, Microelectronic Engineering 53, 69-76 (2000).

[3] S Inoue, K Kajikawa, Mater. Sci. Eng. B103 170-176 (2003).

[4] C. F. Carlström, R. van der Heijden, F. Karouta, R. W. van der Heijden, H. W. M. Salemink, E. Van der Drifft, J. Vac. Sci. Technol. B 24, (2006).

[5] A. Xing, M. Davanco, D. J. Blumenthal, E. L. Hu, J. Vac. Sci. Technol. B 22, 70-73 (2004).

[6] A. P. Mahorowala, H. H. Sawin, J. Vac. Sci. technol. B 20 1077-1083 (2002).

[7] A. Blauw, E. Van Der Drift, G. Marcos, A. Rhallabi, J. of Appl. Phys. 94, 6311 (2003).

[8] G. Marcos, A. Rhallabi, P. Ranson, J. Vac. Sci. Technol. B, 22, No. 4, (2004).

[9] M. A. Vyvoda, M. Li, D. B. Graves, J. Vac. Sci. Technol. B 18, 820-833 (2000).

[10]F. Pommereau, L. Legouezigou, S. Hubert, Sainson, J. P. Chandouineau, S. Fabre, G.H. Duan, B. Lombardet, R. Ferrini, R. Houdre, J. Appl. Phys. 95, 2242 (2004).

[11] M. Fujita, A. Sugitatsu, T. Uesugi, S. Noda, Jap. J. of Appl. Phys., Part 2, 43, 11A, (2004).

[12] A.P. Milenin, C. Jamois, T. Geppert, U. Gosele, R.B. Wehrspohn, Microelec. Engin. 81, 1521 (2005).

[13] J. W. Lee, E.S. Lambers, C.R. Abernathy, S. J. Pearton, R.J. Shul, F. Ren, W. S. Hobson, C. Constantine, Mater. Sci. in Semi. Proc. 1, 65-73 (1998).

[14] J. Lu, X. Meng, A. J. Spring Thorpe, F.R. Shepherd, M. Poirier, J. Vac. Sci. technol. A 22, 1058-1061 (2004).

[15] B.Liu, J.P. Landesman, J.L. Leclercq, A.Rhallabi, S. Guilet, C. Cardinaud, F. Pommereau, M.Avella, M.A. González, J. Jiménez, Mat. Sci. in Semicon. Proc., 9, 1-3, 225-229 (2006).

[16]K. Nishikawa, T. Oomori, K. Ono, J. Vac. Sci. Technol. B 17 127-137 (1999).

[17] F. Neuilly, J. P. Booth, L. Vallier, J. Vac. Sci. Technol. A 20, 225-229 (2002).

[18] M.V. Malyshev, V. M. Donnelly, S. Samukawa, J. Appl. Phys. 84 1222-1229 (1998).

[19] M. V. Malyshev, V. M. Donnelly, J. Appl. Phys. 87, 1642-1649 (2000).

[20] M. V. Malyshev, V. M. Donnelly, J. Appl. Phys. 84, 137-145 (1998).

[21] M. V. Malyshev, N. C. M. Fuller, K. H. A. Bogart, and V. M. Donnelly, I. P. Herman, J. Appl. Phys. 88 2246-2251 (2000).

[22] S. Yonemura, K. Nanbu, K. Sakai, Jpn. J. Appl. Phys. 41, 6189-6196 (2002).

[23] K. Nanbu, T. Morimoto, M. Suetani, IEEE Trans. on Plasma Sci. 27, 1379 - 1388 (1999).

[24] A.M. Efremov, G. H. Kim, J. G. Kim, A.V. Bogomolov, C.I. Kim, Microelec. Enginee. 84, 136-143 (2007).

[25] T. J. Sommerer, M. J. Kushner, J. Vac Sci. Technol. B 10 2179-2187 (1992).

[26] A. Rhallabi, Y. Catherine, IEEE Trans. on Plasma Sci, 19,(1991).

[27] C. Lee, M. A. Lieberman, J. Vac. Sci. Technol. A 13, 368-380 (1995).

[28] C. Lee, D. B. Graves, M. A. Lieberman, D. W. Hess, J. electrochem. Soc. 141, 1547 (1994).

[29] P. J. Chantry, J. Appl. Phys. 62, 1141 (1987).

[30] M. V. Kurepa, D. S. Belie, J. Phys. B. 11, 3719 (1978).

[31]M. A. Lennon, K. L. Bell, H. B. Gilbody, J. G. Hughers, A. E. Kingston, M. J. Murray, F. J. Smith, J. Phys. Chem. Ref. Data 17, 1285 (1988).

[32] T Czerwiec, F Greer, D B Graves, J. Phys. D: Appl. Phys. 38, 4278-4289 (2005).

[33] N. C. M. Fuller, Irving P. Herman, J. Appl. Phys., 90, 3182-3191 (2001).

[34] M. E. Barone, D. B. Graves, J. Appl. Phys. 78, 6604 (1995).

[35] H. Yamada, S. Hamaguchi, J. Appl. Phys., 96, 6147-6152 (2004).

[36] L. Houlet, A. Rhallabi, G. Turban, J. Vac. Sci. Technol. A 17, 2598 (1999). 
[37] A. Jenichen, C. Engler, Surf. Sci. 561, 171-182 (2004).

[38] J. F. Ziegler, TRIM (the Transport of Ions in Matter), IBM-Research, 28-0, Yorktown, NY 10598.

[39] G. Marcos, A. Rhallabi, P. Ranson, Appl. Surf. Sci. 254, 3576-3584 (2008).

[40] S. Bouchoule, G. Patriarche, S. Guilet, L. Gatilova, L. Largeau, and P. Chabert, J. Vac. Sci. Technol. B 26, 666 (2008).

[41] G.A. Curley, L. Gatilova, S. Guilet, S. Bouchoule, G. S. Gogna, N. Sirse, S. Karkari, J-P. Booth, J. Vac. Sci. Technol. A 28, 360 (2010).

[42] R. Chanson, N. Vaissière, A. Rhallabi, C. Cardinaud, M.-C. Peignon, S. Bouchoule, paper CTP.00021, 63rd Annual Gaseous Electronics Conference and 7th International Conference on Reactive Plasmas, GEC-IRCP 2010, Paris, France, October 4-8, (2010).

[43] P. C. Cosby, H. Helm, SRI Report, PYU 1147/MP 92-280 (1992).

[44] G. L. Rogoff, J. M. Kramer, R. B. Piejak, IEEE Trans. Plasma Sci. PS-14, 103 (1986).

[45] R. A. Gottscho, G. R. Scheller, T. Intrator, D. B. graves, J. Vac. Sci. Technol. A6, 1393 (1988).

[46] G. R. Scheller, R. A. Gottscho, T. Intrator, D. B. Graves, J. Appl. Phys. 64, 4384 (1988).

[47] G. R. Scheller, R. A. Gottscho, D. B. Graves, T. Intrator, J. Appl. Phys. 64, 598 (1988).

[48] D. Rapp, P. Englander-Golden, J. Chem. Phys. 43, 1464 (1965).

[49] L. R. Peterson, J. E. Allen, Jr., J. Chem. Phys. 56, 6068 (1972).

[50] D. Margreiter, H. Deutsch, T. D. Mark, Contrib, Plasma Phys. 30, 487 (1990).

[51] P. S. Ganas, J. Appl. Phys. 63, 277 (1988).

[52] N. L. Bassett, D. J. Economou, J. Appl. Phys. 75, 1931 (1994)

[53] L. A. Gundel, D. W. Setser, M. A. A. Clyne, J. A. Coxon, W. Nip, J. Chem. Phys. 64, 4390 (1976). 